\title{
Risk-based Analysis of Pressurized Vessel on LNG Carriers in Harbor
}

\section{Thaddeus Chidiebere NWAOHA ${ }^{1}$, Sidum ADUMENE ${ }^{2}$}

\author{
${ }^{1}$ Federal University of Petroleum Resources, Nigeria \\ ${ }^{2}$ Rivers State University, Nigeria \\ nwaoha.thaddeus@fupre.edu.ng; ORCID ID: https://orcid.org/0000-0002-8687-5558 \\ sidum.adumene@ust.edu.ng; ORCID ID: https://orcid.org/0000-0003-4095-467X \\ Corresponding Author: Thaddeus Chidiebere NWAOHA
}

\begin{abstract}
The need to understand the associated risks of pressurized vessels and their consequences onboard ship is imperative. The handling and storage of Liquefied Natural Gas (LNG) mostly result in catastrophic accident with associated consequences. To quantify these consequences in terms of death and degree of burn depends on the tank structures and pressure control mechanism onboard LNG carriers in a harbor. In this research, the result of the potential risks and damage consequences of the LNG fire accident in terms of the degree of burns and fatality is presented. The probability of death, first and second degree of burn injuries are assessed using consequence modelling technique, while the pool fire was modelled using the Boiling Liquid Expanding Vapour Explosion (BLEVE) approach. The result shows that at 30 meters from the flame radius, the probabilities for first-degree burn, second-degree burn, and death decrease, respectively. A sensitivity analysis revealed that at the initial heat flux and closer distance of $5 \mathrm{~m}$ to $10 \mathrm{~m}$ from the flame radius at the point of the accident, the death rate, first degree, and second-degree burns increase significantly. Therefore, installing a safety system and best practices that will mitigate these risks to as low as reasonably possible should be incorporated into the system design.
\end{abstract}

\section{Keywords}

LNG Carriers, Risk, Harbor, Fire, Explosion, Accidents.

\section{Introduction}

The oil and gas industries store large volumes of flammable and hazardous chemicals in tanks, including LNG. Hydrocarbon products are highly volatile. Once there is any fuel-air mixture in or around the storage tank, ignition occurs, which results in a fire and explosion accident. Research has shown that most of these accidents occurred during cleaning, storage, maintenance, anti-rusting, spraypainting, welding, loading, unloading work, etc., [1]. Such exercises have resulted in severe fire and explosion accidents with several global consequences $[2,3]$. Other examples where such activities resulted in fire and explosion accidents are the Bayamon oil storage facility fire in Puerto 
Rico [4], and the Indian Oil Corporation Ltd explosion accident [5]. Severe environmental pollutions, casualties and economic losses have resulted from fire and explosion of stored hydrocarbon. This points to how safety-critical hydrocarbon storages are.

Hydrocarbon products, especially the LNG, have a high level of risk of fire and explosion. Therefore, it is imperative to study and analyze the risk and consequences of fire and explosion accidents in LNG stored vessels. This research's main objective is to analyze the risk associated with LNG stored in a pressurized tank in a harbor and evaluate the consequences on the people and environment. A fire accident scenario was considered in the study. The research analysis examined a pool fire case study. Risk and consequence analysis models were adopted to demonstrate the case study to assess the degree of impact or damage of the pressurized vessel's fire and explosion. This enables the prediction of the frequencies of possible accidents and the quantitative assessment of both societal risk and individual risk.

\section{Review of Relevant Literature}

\subsection{Risk Assessment and Methodology}

Risk is a phenomenon that measures the impact of a hazardous event on the environment, human or economic loss in terms of the incident likelihood and the magnitude of the injury, damage, or loss [6]. Similarly, risk can be defined in terms of the combination of the probability of a hazardous event and the consequences of occurrence [7]. Risk analysis involves risk estimation, information integration about scenarios from the estimated risk, frequencies of occurrence, and consequences [7].

Risk indices are being used by researchers to correlate the magnitude of the risk on people and facilities. For example, a risk ranking matrix has been used to assess various risk levels regarding harm probability and severity categories. This is presented in the two-dimensional framework for likelihood and consequences [8]. Based on this approach, the risk is characterized by categorizing probabilities and consequences on the matrix axes. Risk effect categorization may be individualized or societal. Individual risk is characterized by the likelihood of an individual death per year from an exposed distance to the source of hazard [6]. It is also essential to evaluate the societal risk of pressurized tank fire and explosion, which defined the probability of death of a group of people exposed to hazardous events [9]. It is quantified based on the number of persons involved in the accident. In multiple causality events (accidents), the frequency distribution is commonly represented on the cumulative frequency versus number of fatalities plot (i.e., the F-N curve ) [9].

Societal risk effects are mostly presented using a quantitative approach for the hydrocarbon industries. Vulnerability rate describes the degree of exposed threat, the capability to suffer harm, and the extent to which various social groups are at risk [10]. In their research, Li et al. [11] estimated the individual risk of a natural gas pipeline failure under pressure. The authors proposed the "exposuresensitivity-resilience" framework to capture the social-ecological indicators of the associated risk of natural gas pipeline hazards. However, to adequately capture the risk indicators, CPS/AICHE [12] provides criteria for individual risk and societal risk estimation due to exposure to adverse/major accidents in the chemical, oil and gas industries. Fire and explosion accident analysis was presented by [1] for oil depots, and the result of the study shows that most of the common accidents are due to the vapor cloud explosion. This accident type and its management should be targeted by minimizing/controlling 
the predisposing causes. Rigas and Sklavounos [13] investigated various accident scenarios based on real data, using quantitative statistical estimation. Jianhua and Zhenghua [14] analyzed fire and explosion onboard LNG ships. They used the DOW Chemical Exposure Index (CEI) criteria, BLEVE model, and Vapor Cloud Explosion (VCE) model to predict the consequences of fireball without considering the probability of impact on the environment. Also, in [15], the authors present a review of LNG application for ship and land transportation, respectively. They further examined different methods for LNG based analysis, likely accidentprone operations, and the necessary precaution during operation. To further examined the effect of LNG operation, [16] considered the overpressure against the accident's distance of impact and thermal intensity. Therefore, this work seeks to analyze pool fire explosion consequence using the BLEVE model, thermal radiation model, and probabilistic function (probit function) for an LNG carrier at harbor. This will help to reliably evaluate the consequences in terms of burns and death.

\section{Methodology}

The common modeling algorithm for consequence analysis is shown in Figure 1 [12]. The model estimates the impacts of flammable explosion and release of toxic material due to the loss of containment or system failure on the environment, human, and assets numerically.

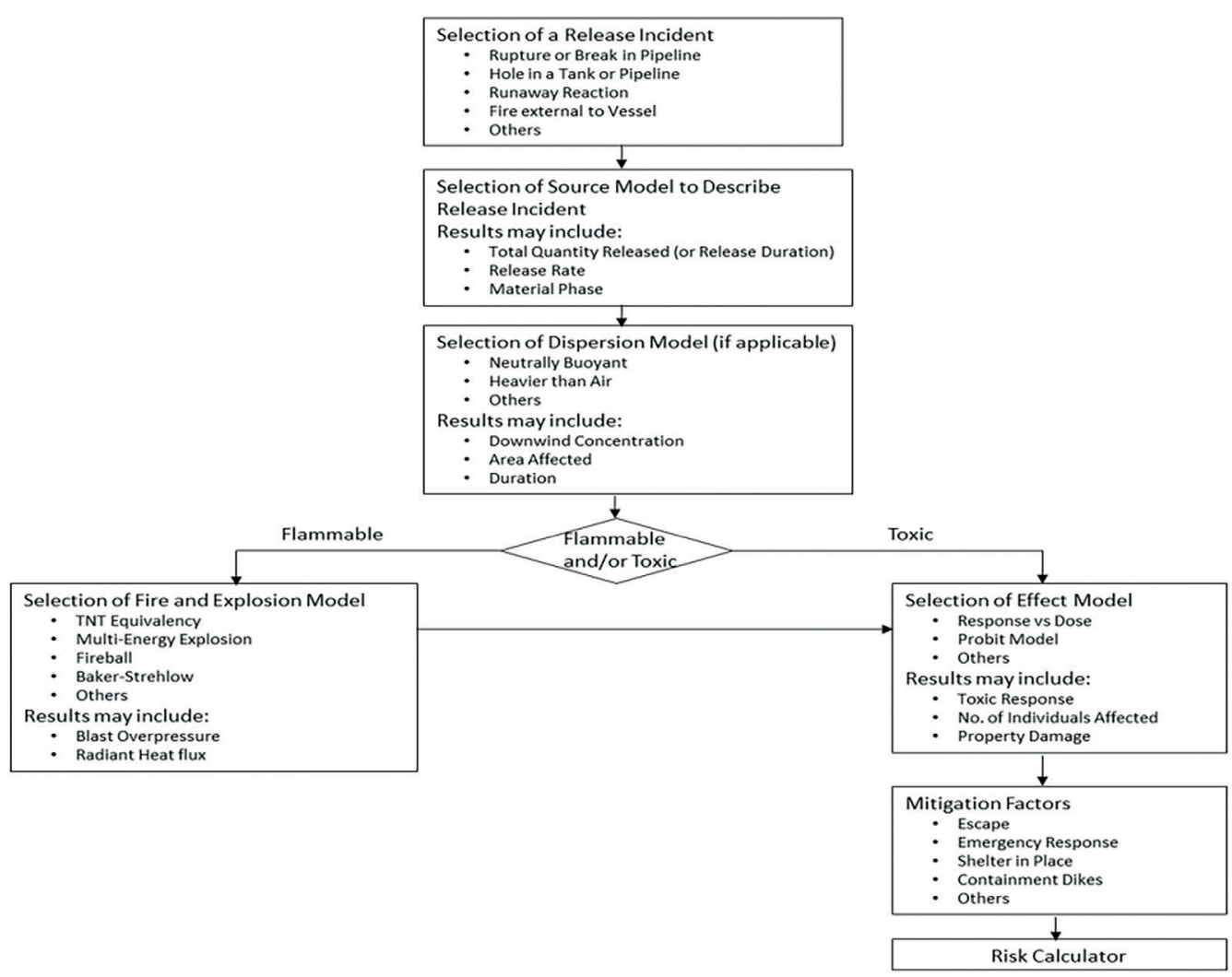

Figure 1. Logic Diagram for Consequence Models due to Releases of Volatile Hazardous Substances [12] 


\subsection{Individual and Societal Risk Analysis}

To model the individual risk, the likelihood of injury to the individual at the period over which the injury might occur need to be estimated [3]. This is expressed in terms of the exposed likelihood, such as death and is usually quantified as a risk per year [9], as shown by equation (1).

$$
\text { Individual risk of exposure (average) }=\frac{\text { Number of fatalities }}{\text { Number of people at risk }}
$$

For a geographical location defined by $x, y$ within a period, $\mathrm{t}$, the individual exposed risk can be estimated using equation (2) [12]:

$$
\mathrm{I} R_{x, y}=\sum_{i=1}^{n} \mathrm{I} R_{x, y, \mathrm{i}}
$$

where $I R_{x, y}$ describe the total number of persons at risk (fatality) due to the exposure for a given geographic location, while $I R_{x, y, i}$ is for an individual risk of exposure (fatality) based on the characterized $x, y$ geographical location due to a hazard event, $i$. The upper bound $n$ describes the total number of individuals exposed based on the accidental release.

The risk of individual exposure (fatality) due to a hazard event, $i, \mathrm{I} R_{x, y, i}$ is modeled using equation (3)

$$
\mathrm{I} R_{x, y, \mathrm{i}}=f_{i} P f_{i}
$$

where $f_{i}$ describes the rate of hazard event i, outcome, $P_{f i}$ indicates the likelihood that the hazard event $i$, the outcome will be fatal for the operating $x, y$ characterizes geographical location.

The rate $f i$ of a hazard event outcome can be estimated by equation (4)

$$
f_{i}=F_{i} P_{o i} P_{o c i}
$$

where $F_{i}$ describes the rate of occurrence of the hazardous event, with an associated outcome case $i$, while $P_{o i}$ indicates the likelihood that the hazard event occurs with the associated outcome case, $i$. $P_{o c i}$ defines the likelihood of the hazardous event outcome case i occurrence depending on the prior circumstance of the precursor incident $i$ and its corresponding outcome case.

For societal risk analysis, the relationship that describes the rate of hazardous exposures and the number of people exposed due to the accidental release need to be established [9]. These two measures are essential for a wellinformed risk mitigation/reduction criteria adapted for facility operation assessing the benefits of risk reduction measures or acceptability criteria for risk critical facility. Equation (5) is used to predict societal risk [9]:

$$
\mathrm{N}_{i}=\sum_{x, y} P_{x, y} P_{f, i}
$$

where $N_{i}$ describes the outcome of the hazardous event, $i$, (that is the number of fatalities as a result of the hazard event), $P_{x, y}$ indicates the population at the geographical location that the hazardous event occurs, and $P_{f i}$ indicates the likelihood that the hazardous event $i$, the outcome will be fatal for the operating $x$, $y$ characterizes the geographical location.

\subsection{Hazard Impact Assessment}

The complete risk assessment due to hazardous events involves predicting the fatality likelihood at a given exposure. The fatality likelihood as a result of the exposure death is calculated using Probit Function (see equation (6)) [17]. Effect assessment models are adopted to measure the degree of impact of the exposure. The hazard incident outcome can be due to different factors, as reported by [13]. 


$$
P_{r}=c_{1}+c_{2} \operatorname{InD}
$$

where $P_{r}$ represents the probit, $C_{1}$ is a model constant that is dependent on the type of injury, $C_{2}$ is also constant, which depends on the load type. $D$ is the load. A conversion table from probit to percentage was provided by [12]. For different hydrocarbons, the modeling constants $c_{1}, c_{2}$ are provided [12].

\subsection{Consequence Assessment}

This involves an analytical modeling tool to assess the hazard potential and subsequently translate into potential consequences (e.g., harm to people, pollution to the environment, or damage to the asset). To calculate the number of burns due to exposure or fatality, the thermal dose ought to be quantified. Mathematically, the thermal dose is expressed in term of the exposure time and the heat flux as presented by equation (7) [18]:

$$
D=t_{e f f}\left(\mathrm{q}^{\prime}\right)^{4 / 3}
$$

$\mathrm{q}^{\prime}=$ calculated heat flux in $\mathrm{W} / \mathrm{m}^{2}$

$t_{\text {eff }}=$ the effective exposure time of a person to heat flux in (seconds)

For a fire pool developed in an area where the population is high, that is about 1 person per $20 \mathrm{~m}^{2}$ (in the whole area), the probability of injury ( first or second-degree burns) and death in $30 \mathrm{~m}$ from the flame's surface in terms of the number of the persons with first and second-degree burns, and fatality will be calculated by equation (10).

For the case study, the heat flux will be calculated as $\mathrm{q}^{\prime}=26.964 \mathrm{e}^{-00238 \times 30}=13.2$ $\mathrm{KW} / \mathrm{m}^{2}$ for $30 \mathrm{~m}$. For $\mathrm{U}=4 \mathrm{~m} / \mathrm{s}, \mathrm{Xo}_{\mathrm{o}}=138.42 \mathrm{~m}$ (at $138.4 \mathrm{~m}, \mathrm{q}^{\prime}=1 \mathrm{~kW} / \mathrm{m}^{2}$ ) and $\mathrm{r}=30 \mathrm{~m}$. The exposure time was calculated as:

$$
t_{\text {eff }}=t_{r}+\frac{\left(x_{o}-r\right)}{u}
$$

where; $t_{r}=$ person' $\mathrm{s}$ response time in (s)

$\mathrm{X}_{\mathrm{o}}=$ is the distance between the flame's surface and the position where the intensity of the heat flux is lower than $1 \mathrm{~kW} / \mathrm{m}^{2}$ in (m)

$r=$ the distance of the person from the surface of the flame in $(\mathrm{m})$

$\mathrm{u}=$ the escape velocity in $(\mathrm{m} / \mathrm{s})$

$$
\begin{gathered}
t_{\text {eff }}=5+\frac{(138.42-30)}{4} \\
t_{\text {eff }}=32.11 \mathrm{~s}
\end{gathered}
$$

The thermal radiation dose was calculated "as"

$D=32.11 \times(13.204)^{4 / 3}=10.02 \times 10^{6} \mathrm{~W}^{4 / 3} \mathrm{sm}^{-8 / 3}$

\subsubsection{The Probability of Death or Injury}

The number of fatalities or injured persons due to exposure could be predicted based on the Probit function. The Probit function is widely employed due to its broad applicability in assessing the risk involved in fire accidents. The probability of death or injury (P), because of a specific thermal dose is given by equation (9):

$$
\mathrm{P}=\mathrm{F}_{\mathrm{k}} \frac{1}{2}\left[1+\operatorname{erf}\left(\frac{\mathrm{Pr}-5}{\sqrt{2}}\right)\right]
$$

\section{Results and Discussion}

This research assesses the risk involved if a pool fire should occur in an LNG storage tank on an LNG carrier in harbor. A case study data as recorded in [18] was adopted with the following as input parameters: "Boiling temperature, $\mathrm{T}_{\mathrm{b}}=423 \mathrm{k}$; Heat of Combustion, $\Delta \mathrm{Hc}=45,000 \mathrm{KJ} / \mathrm{Kg}$; Heat of Vaporization, $\Delta \mathrm{Hv}=370 \mathrm{KJ} / \mathrm{Kg}$; Specific heat capacity, $\mathrm{CP}=$ $2.21 \mathrm{KJ} / \mathrm{Kgk}$. Ambient temperature, $\mathrm{T}_{\mathrm{a}}=298$ $\mathrm{k}$; Soot surface-emitting power, SEPsoot $=20$ $\mathrm{KW} / \mathrm{m}^{2}$; Wind velocity, uw= $5 \mathrm{~m} / \mathrm{s}$; Density of air, $p_{\text {air }}=1.21 \mathrm{Kg} / \mathrm{m}^{3}$; Viscosity of air, $\eta_{\text {air }}=16.7 \mu \mathrm{Pas}$, 
Saturation water vapour pressure, $\mathrm{P}_{\mathrm{w}}=2320$ $\mathrm{P}_{\mathrm{a}}$; Relative humidity, $\mathrm{RH}=0.7$ "

For this research, $F_{k}$ value of 0.40 was chosen to account for its influence in the probability estimation. The coefficients $C_{1}$ and $C_{2}$ have values depending on the death and degree of burn. The values of these coefficients can be obtained from Table1.

Table 1. Coefficients $c_{1}$ and $c_{2}$ [12]

\begin{tabular}{|l|c|c|}
\hline \multicolumn{1}{|c|}{ Effect } & $\boldsymbol{c}_{\boldsymbol{1}}$ & $\boldsymbol{c}_{\boldsymbol{2}}$ \\
\hline $\mathbf{1}^{\text {st }}$ degree burn & -39.83 & 3.0186 \\
\hline $\mathbf{2}^{\text {nd }}$ degree burn & -43.14 & 3.0186 \\
\hline Deaths & -36.38 & 2.56 \\
\hline
\end{tabular}

The probit function for the $1^{\text {st }}$ degree burn is given as follows:

$$
\begin{gathered}
\operatorname{Pr}=-39.83+3.0186 \ln \left(10.02 \times 10^{6}\right) \\
\operatorname{Pr}=8.83
\end{gathered}
$$

The probability of $1^{\text {st }}$ degree burns at $\mathrm{r}=30 \mathrm{~m}$ is calculated as:

$$
\begin{gathered}
P=0.4 * \frac{1}{2}\left[1+\operatorname{erf}\left(\frac{8.83-5}{\sqrt{2}}\right)\right] \\
P=0.3999
\end{gathered}
$$

The probit function for the $2^{\text {nd }}$ degree burn is given as follows:

$$
\begin{gathered}
\operatorname{Pr}=-43.14+3.0186 \ln \left(10.02 \times 10^{6}\right) \\
\operatorname{Pr}=5.5212
\end{gathered}
$$

The probability of $2^{\text {nd }}$ degree burns at $\mathrm{r}=30 \mathrm{~m}$ is calculated as:

$$
\begin{gathered}
\mathrm{P}=0.4 * \frac{1}{2}\left[1+\operatorname{erf}\left(\frac{5.52-5}{\sqrt{2}}\right)\right] \\
P=0.2794
\end{gathered}
$$

The probit function for deaths is given as:

$$
\begin{gathered}
\operatorname{Pr}=-36.38+2.56 \ln \left(10.02 \times 10^{6}\right) \\
\operatorname{Pr}=4.887
\end{gathered}
$$

The probability of deaths at $r=30 \mathrm{~m}$ is calculated as:

$$
\begin{gathered}
P=0.4 * \frac{1}{2}\left[1+\operatorname{erf}\left(\frac{4.887-5}{\sqrt{2}}\right)\right] \\
P=0.1822
\end{gathered}
$$

The probabilities of $1^{\text {st }}, 2^{\text {nd }}$ degree burns, and deaths are $0.3999,0.2794$, and 0.1822 . The predicted impact at varying distance from the center of the flame is shown in Table 2 and Figure 2.

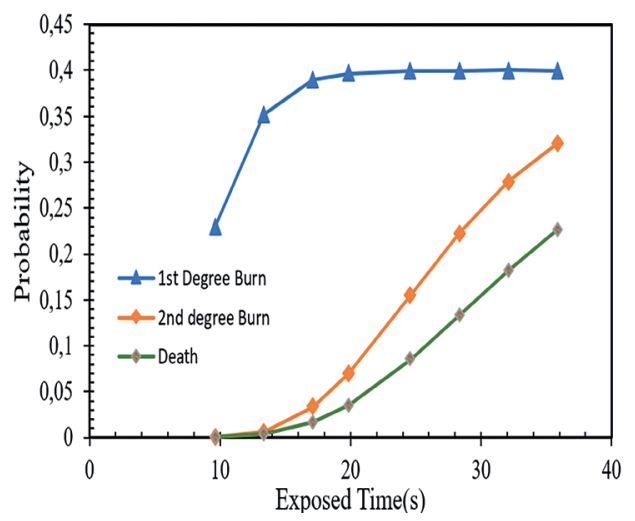

Figure 2. Predicted Impact at Varying Distance from Center of Flame

The result shown in Figure 2, gives the probability of impact with respect to the time of exposure to thermal radiation dose during fire accident. It shows that the probability of burn or death increase with the time of exposure. This indicates that as the person's duration of exposure to the thermal radiation dose increases, the likelihood of impact increases accordingly. However, for the 1st degree burn, there is an asymptotic characteristic as the time of exposure increases, as shown. 


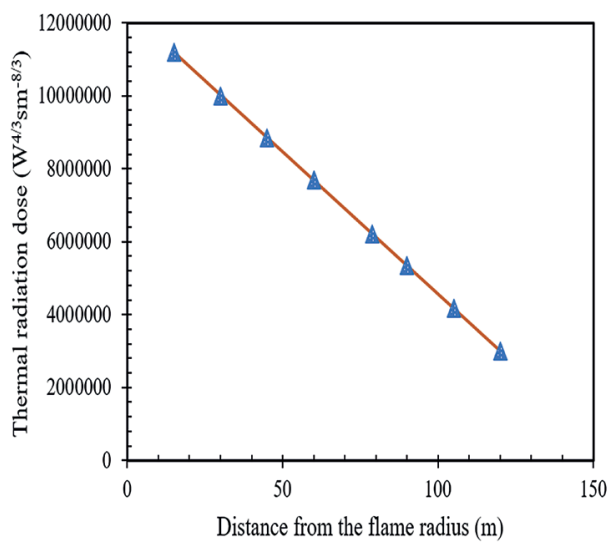

Figure 3. Thermal Radiation Dose-effect Against Flame Radius Distance

The result shows that the probability of burn and death increases with the rate of exposure to fire or explosion. This implies that an increase in the exposure time increases the degree of burn on the individual. Also, as the distance from the flame center increases, the probability of impact gradually decreases, as shown in Table 2. Figure 3 shows that the thermal radiation dose-effect decreases correspondingly at the farther distance from the radius of the flame. Hence, critical firework or accident causative factors should be monitored in case of maintenance work.

\subsection{The Total Number of Victims in the Pool Fire Accident}

Having calculated the probabilities of burns (whether 1st or 2nd degrees), equation (10) is used to calculate the number of victims who died and/or sustained the two degrees of burns, as mentioned.

$$
\mathrm{N}=\left(\mathrm{N}_{o} \pi \mathrm{R}^{2}\right)+\int_{R}^{\infty} P \mathrm{~N}_{\mathrm{o}} 2 \pi \mathrm{rdr}
$$

$\mathrm{N}_{\mathrm{o}}$ - the number of persons $/ \mathrm{m}^{2}$

$\mathrm{R}$ - radius of the fire

The first term in the expression used to predict the number of fatality within the fire radius, and the second term (including the corresponding probit function for death) is used to estimate the number of deaths outside the fire flame radius. Calculations of the number of victims who suffered $1^{\text {st }}$ or $2^{\text {nd }}$ degree burns are calculated using the second term (with their appropriate probit functions).

Table 2. Predicted Probability of Burns and Death at Varying Distances from the Flame and Exposed Hours

\begin{tabular}{|c|c|c|c|c|c|c|c|c|}
\hline $\begin{array}{c}\text { Distance } \\
\text { from } \\
\text { Flame } \\
(\mathbf{m})\end{array}$ & $\begin{array}{c}\text { Exposed } \\
\text { Time } \\
\mathbf{( s )}\end{array}$ & $\begin{array}{c}\text { Thermal } \\
\text { Radiation } \\
\text { Dose } \\
\left.\mathbf{W}^{\mathbf{4} / \mathbf{3}} \mathbf{s m}^{-8 / 3}\right)\end{array}$ & $\begin{array}{c}\text { Probit } \\
\mathbf{1}^{\text {st }} \\
\text { degree } \\
\text { burn }\end{array}$ & $\begin{array}{c}\text { Probit } \\
\mathbf{2}^{\text {nd }} \\
\text { degree } \\
\text { burn }\end{array}$ & $\begin{array}{c}\text { Probit } \\
\text { Death }\end{array}$ & $\begin{array}{c}\text { Probability } \\
\mathbf{1}^{\text {st }} \\
\text { Degree } \\
\text { Burn }\end{array}$ & $\begin{array}{c}\text { Probability } \\
\mathbf{2}^{\text {nd }} \text { Degree } \\
\text { Burn }\end{array}$ & $\begin{array}{c}\text { Probability } \\
\text { of Death }\end{array}$ \\
\hline 15.00 & 35.85 & 11183757.33 & 9.16180 & 5.85180 & 5.16873 & 0.39999 & 0.32113 & 0.22680 \\
\hline 30.00 & 32.10 & 10013908.24 & 8.82828 & 5.51828 & 4.88588 & 0.39997 & 0.27915 & 0.18183 \\
\hline 45.00 & 28.35 & 8844059.14 & 8.45328 & 5.14328 & 4.56786 & 0.39989 & 0.22279 & 0.13313 \\
\hline 60.00 & 24.60 & 7674210.05 & 8.02500 & 4.71500 & 4.20464 & 0.39950 & 0.15513 & 0.08528 \\
\hline 79.00 & 19.85 & 6192401.19 & 7.37738 & 4.06738 & 3.65541 & 0.39651 & 0.07020 & 0.03575 \\
\hline 90.00 & 17.10 & 5334511.86 & 6.92723 & 3.61723 & 3.27365 & 0.38921 & 0.03335 & 0.01686 \\
\hline 105.00 & 13.35 & 4164662.77 & 6.17994 & 2.86994 & 2.63989 & 0.35240 & 0.00663 & 0.00365 \\
\hline 120.00 & 9.60 & 2994813.68 & 5.18455 & 1.87455 & 1.79572 & 0.22928 & 0.00036 & 0.00027 \\
\hline
\end{tabular}


Given that the population density at the terminal is 1 person per $30 \mathrm{~m}^{2}$, implying that $\mathrm{No}$ is 0.033 persons $/ \mathrm{m}^{2}$ and the radius of the petrol pool calculated as $21.22 \mathrm{~m}$, the number of deaths inside the radius of the fire is calculated as:

$$
\begin{gathered}
\mathrm{N}=\operatorname{No\pi } \mathrm{R}^{2}=0.033 \times 3.142 \times(21.22)^{2} \\
\mathrm{~N}=46.69 \approx 47 \text { workers }
\end{gathered}
$$

Calculating the number of deaths outside the fire radius and victims with $1^{\text {st }}$ and $2^{\text {nd }}$ degrees of injury requires a probability relation expressed in terms of $r$, the distance from the flame's surface to the farthest point in the area under consideration $(30 \mathrm{~m})$. Thus, a general expression for thermal dose D is obtained as follows:

$D=(3202.4603+20.215 r) e^{-0.031733 r}$

Appropriate probability expressions are then obtained that incorporate corresponding probit function expressions with appropriate $C_{1}$ and $C_{2}$ values. The integrals based on equation (10) is used to predict the number of death as shown:

The number of deaths is:

$$
\begin{aligned}
& \mathrm{N}=0.04147 \int_{21.22}^{\infty} \mathrm{r}[1+\operatorname{erf}(-29.26+1.810 \ln \\
& \left.\left.\left((3202.4603+20.215 \mathrm{r}) \mathrm{e}^{-0.031733 \mathrm{r}}\right)\right)\right] \mathrm{dr}
\end{aligned}
$$

The number of victims who sustained $1^{\text {st }}$ degree burns is:

$$
\begin{aligned}
& \mathrm{N}=0.04147 \int_{21.22}^{\infty} \mathrm{r}[1+\operatorname{erf}(-31.70+2.134 \ln \\
& \left.\left.\left((3202.4603+20.215 \mathrm{r}) \mathrm{e}^{-0.031733 \mathrm{r}}\right)\right)\right] \mathrm{dr}
\end{aligned}
$$

The number of victims who sustained $2^{\text {nd }}$ degree burns is:

$$
\begin{aligned}
& \mathrm{N}=0.04147 \int_{21.22}^{\infty} \mathrm{r}[1+\operatorname{erf}(-34.04+2.134 \ln \\
& \left.\left.\left((3202.4603+20.215 \mathrm{r}) \mathrm{e}^{-0.031733 \mathrm{r}}\right)\right)\right] \mathrm{dr}
\end{aligned}
$$

The approximate solutions of the integrals as shown above for the accident scenario, reveals the following:

-66 personnel will suffer $1^{\text {st }}$ degree burns

-14 personnel will suffer $2^{\text {nd }}$ degree burns - 85 deaths (within fire radius, $1^{\text {st }}$ and $2^{\text {nd }}$ degree burns inclusive)

\subsection{Risk Estimation}

The risk associated with the pool fire accident is calculated as the product of the rate of occurrence of the pool fire and the consequence of the fire on workers at the terminal. Thus, the risk associated with each fire consequence is shown below:

-Risk of victims who sustained $1^{\text {st }}$ degree burn $=1.9 \times 10^{-6} \times 66=1.254 * 10^{-4}$ $=0.0001254$ victims $/ \mathrm{km}$ years

-Risk of victims who sustained $2^{\text {nd }}$ degree burn $=1.9 \times 10^{-6} \times 14=2.66 * 10^{-5}$ $=2.66 \times 10^{-5}$ victims $/ \mathrm{km}$ years

- Risk of deaths $=1.9 \times 10^{-6} \times 85=1.615^{*} 10^{-4}$ $=0.0001615$ victims $/ \mathrm{km}$ years

\section{Conclusion}

The adopted methodology for pool fire analysis is advantageous due to its ability to evaluate the probability of the top event (release rate of LNG in the storage tank based on this case study). The combination of several root causes, such as leaks, overpressure, ignition, spark, and the possible consequences of this release, such as numbers of burns and death, were evaluated. The LNG release rate may be due to different root causes since everyone can lead to the release of LNG. The research conclusively shows that: 
- The release rate of $1.712 \mathrm{E}-02$ per $1000 \mathrm{~km}$ years for the leak was observed.

- The probabilities evaluated for $1^{\text {st }}$ and $2^{\text {nd }}$ degree burns and fatality at $30 \mathrm{~m}$ from the flame radius were defined by the fire sphere for the case study.

- For the same heat flux, the fire's impact decreases accordingly based on the distance from the fire flame radius.

- The sensitivity analysis (Table 2) shows the predicted save zone from the incident's point by varying the flame radius and the exposure time. This provides a technical guide on the appropriate safety barrier/action needed for safe maintenance operations.

- The number of deaths, first-degree burn, and second-degree burn at the flame radius range of $5-10 \mathrm{~m}$ decrease respectively with respect to the thermal dose. This indicated that the worker in the harbor within the sphere would suffer the greatest damage (mostly death).

\section{References}

[1] Zhou, Y., Zhao, X., Zhao, J. and Chen, D. (2016). Research on fire and explosion accidents of oil depots. Chemical Engineering Transactions, 51, 163-168. https://doi.org/ 10.3303/CET1651028.

[2] Mather, T.A., Harrison, R.G., Tsanev, V.I., Pyle, D.M., Karumudi, M.L., Bennett, A.J., Sawyer, G. M. and Highwood, E. J. (2007). Observations of the plume generated by the December 2005 oil depot explosions and prolonged fire at Buncefield (Hertfordshire, UK) and associated atmospheric changes. Proc. of Royal Society A, (463), 1153-1177. https://doi. org/10.1098/rspa.2006.1810.

[3] Yifei, M., Dongfeng, Z., Yi, L. and Wendong, W. (2012). Study on performance- based safety spacing between ultra large oil tanks. Process Safety Progress, 34, 398-410. https://doi.org/10.1002/ prs.11526.
[4] Godoy, L. A. and Batista-Abreu, J. C. (2012). Buckling of fixed-roof aboveground oil storage tanks under heat induced by an external fire. Thin-Walled Structures, 53, 90-101. https://doi.org/10.1016/j. tws.2011.12.005.

[5] Sharma, R.K., Gurjiar, B.R., Wate, S.R., Ghuge, S.P. and Agrawal, R. (2013). Assessment of an accidental vapour cloud explosion: Lessons from the Indian Oil Corporation Ltd. accident at Jaipur, India. Journal of Loss Prevent in the Process Industries, 26, 82-90. https://doi.org/10.1016/j. jlp.2012.09.009.

[6] Modarres, M. (2006). Risk analysis in engineering: techniques, tools, and trends. CRC Press, Taylor \& Francis Group, Boca Raton.

[7] Khan, F. I. and Abbasi, S. A. (1998). Techniques and methodologies for risk analysis in chemical process industries. Journal of Loss Prevention in the Process Industries, 11(4), 261-277. https://doi.org/10.1016/ S0950-4230(97)00051-X.

[8] Weber, M. (2006). Some safety aspects on the design of sparger systems for the oxidation of organic liquids. Process Safety Progress, 25(4), 326-330. https://doi. org/10.1002/prs.10143.

[9] Renjith, V. R. and Madhu, G. (2010). Individual and societal risk analysis and mapping of human vulnerability to chemical accidents in the vicinity of an industrial area. International Journal of Applied Engineering Research, 1(1), 135-148.

[10] De Souza Porto, M. F. and De Freitas, C. M. (2003). Vulnerability and industrial hazards in industrializing countries: An integrative approach. Futures, 35(7), 717-736. https:// d o i . org/ $10.1016 /$ S 0016 3287(03)00024-7. 
[11] Li, Y., Zhang, X., Zhao, X., Ma, S., Cao, H. and Cao, J. (2016). Assessing spatial vulnerability from rapid urbanization to inform coastal urban regional planning. Ocean and Coastal Management. 123, 53-65. https://doi.org/10.1016/j. ocecoaman.2016.01.010.

[12] CPS/AIChE. (1995). Center for Chemical Process Safety. Retrieved from https://www.aiche.org/ccps/ resources/glossary/process-safetyglossary

[13] Rigas, F. and Sklavounos, S. (2004). Major hazards analysis for populations adjacent to chemical storage facilities. Process Safety and Environmental Protection, 82(5 B), 341-351. https://doi.org/10.1205/ psep.82.5.341.44189.

[14] Jianhua, L. and Zhenghua, H. (2012). Fire and explosion risk analysis and evaluation for LNG ships. Procedia Engineering, 45, 70-76. https://doi. org/10.1016/j.proeng.2012.08.123.

[15] Banaszkiewicz, et.al. (2020). Liquefied Natural Gas in Mobile Applications-Opportunities and Challenges. Energies, 13, 5673. https: //doi.org/10.3390/en13215673. https://doi.org/10.3390/ en13215673.

[16] Malviya, K. R. and Rushaid, M. (2018). Consequence analysis of LPG storage tank. Materials Today: Proceedings, 5(2), 4359-4367. https://doi. org/10.1016/j.matpr.2017.12.003.

[17] Crowl, D. A. and Louvar, J. A. (2002). Chemical process safety: fundamentals with applications. Pearson Education.

[18] Assael, M. J. and Konstantinos, E. K. (2010). Fires, Explosions, and Toxic Gas Dispersions: Effects Calculation and Risk Analysis. CRC Press. 